\title{
Development of Tailored Structure and Tensile Properties of Thermomechanical Treated Micro Alloyed Low Carbon Dual Phase Steel
}

\author{
Hany Khalifa1,2*, G. M. Megahed ${ }^{2}$, Taher El-Bitar ${ }^{3}$, Mohamed A. Taha1 ${ }^{*}$ \\ ${ }^{1}$ Faculty of Engineering, Ain-Shams University, Cairo, Egypt \\ ${ }^{2}$ EZZ Steel, Cairo, Egypt \\ ${ }^{3}$ Central Metallurgical R \& D Institute (CMRDI), Helwan, Cairo, Egypt \\ Email: ^hany-khalifa@ezzsteel.com, ^m_ataha@yahoo.com
}

How to cite this paper: Khalifa, H., Megahed, G.M., El-Bitar, T. and Taha, M.A. (2020) Development of Tailored Structure and Tensile Properties of Thermomechanical Treated Micro Alloyed Low Carbon Dual Phase Steel. Materials Sciences and Applications, 11, 851-866.

https://doi.org/10.4236/msa.2020.1112056

Received: October 23, 2020

Accepted: December 19, 2020

Published: December 22, 2020

Copyright $\odot 2020$ by author(s) and Scientific Research Publishing Inc. This work is licensed under the Creative Commons Attribution-NonCommercial International License (CC BY-NC 4.0). http://creativecommons.org/licenses/by-nc/4.0/ (c) (i) (8) Open Access

\begin{abstract}
Direct hot rolled dual phase steel production represents a challenging route, compared with cold rolled and intercritical annealing process, due to complex and sophisticated control of the hot strip mill processing parameters. Instead, high technology compact slab production plant offers economic advantages, adequate control and prompt use of the advanced thermomechanical controlled rolling. The current work aims to obtain different structures and tensile properties by physical simulation of direct hot rolled niobium micro alloyed dual phase low carbon steel by varying the metallurgical temperatures of hot strip mill plant. This starts with adaptation of the chemical analysis of a low carbon content to fall far from the undesired peritectic region to avoid slab cracking during casting. Thermodynamic and kinetics calculations by Thermo-Calc 2020 and JMat pro software are used to define the transformation's temperatures Ae1 and Ae3 as well as processing temperatures; namely of reheating, finishing rolling, step cooling and coiling temperatures. The results show that the increase of finishing rolling temperature from $780^{\circ} \mathrm{C}$ to $840^{\circ} \mathrm{C}$ or decreasing either of step cooling duration at ferrite bay from 7 to 4 seconds, enhances yield and tensile strengths, all due to more martensite volume fraction formation. The yield and tensile strengths also increase with decreasing coiling temperature from $330^{\circ} \mathrm{C}$ to $180^{\circ} \mathrm{C}$, which is explained due to the increase of dislocation densities resulted from the sudden shape change during martensite formation at the lower coiling temperature in additional to the self-tempering of martensite formed at higher coiling temperatures which soften the dual phase steel.
\end{abstract}

\section{Keywords}

Micro-Alloyed Steel, Dual Phase Steel, Thermomechanical Simulation, 


\section{Introduction}

Several studies, in the last decades, demonstrated that dual phase steel retain an improved balance between strength and ductility. The Superior tensile properties can be reached by a composite-like microstructure composed of hard martensite islands impeded in a ductile ferritic matrix [1] [2] [3] [4]. Such specific combination of properties makes dual phase steel an innovative material with superior lightweight applications prospective, progressively used in modern automotive applications in the ULSAB-AVC developments. The usage of dual phase steel in modern automotive applications is predicted to reach $75 \%$ [5]-[10]. There are different possible process routes to produce a dual phase steel. One process consists of reheating a two-phase ferrite and austenite microstructure into the intercritical temperature range with subsequent accelerated cooling [11]-[16]. Alternatively, a dual phase steel can be economically produced within the direct hot deformation schedule, starting with an austenitic microstructure in hot strip mill of CSP integrated plants [17] [18]. The CSP technology offers an economic way to produce a hot rolled strip, with characteristics which are comparable to those of a cold rolled material. Modern CSP plants allow the use of thermomechanical controlled rolling TMCR process to produce DP microstructure [19]. Thermo-mechanical processing is the technique to tailor the mechanical properties of steel which are impossible to realize by thermal treatments or forming operations alone [20]. It is therefore a sophisticated combination of a well-defined thermal path and a well-defined deformation path [21]. The development of new product or optimizing current product generally must pass an intensive research period of lab simulations and computer modelling to generate the arguments which will convince the people in the operating lines [6]. Therefore, the current work carried out the necessary thermodynamic calculation, kinetics calculations, alloy design as an intensive off-line preparation, utilized the advances in thermomechanical simulation process by using physical simulator to simulate HSM production process before commence in the costly industrial trails in the CSP plant.

\section{Aim and Approach}

In this work, low carbon micro-alloyed steel for CSP plants, which achieves crack-free cast slab by avoiding the two phases in the peritectic region. Limiting the amount of carbon in the concept of the steel improves the weldability which is of primary importance for automotive industry. Applying a combination of thermo-mechanical rolling and a well-defined cooling schedule that allows grain refinement, dissolution of niobium carbides $\mathrm{NbC}$ during reheating and precipi- 
tation during cooling. These aims are attained by physical simulation of the manufacturing of direct hot rolled steel in hot strip mill of the integrated CSP technology which combines steel making, refining, alloying, casting and rolling for the same heat in the continued production line.

Micro alloying concept is applied to achieve high strength levels by grain refinement and precipitation hardening, through adding of $0.04 \mathrm{Wt} \% \mathrm{Nb}$ as a micro-alloying element. The work objective is to produce various DP steel grades from the same chemical composition (low carbon) by means of control of the main metallurgical processing temperatures and the isothermal ferrite holding time. By adaption of the cooling rate and holding time in the high temperature phase transformation region, the amount of polygonal ferrite is regulated. Martensite is then formed from the non-transformed austenite during the subsequent quenching process. The control of final cooling and coiling temperature determines the nature of the second phase. For process simulation, thermodynamic and kinetics calculations were executed by Thermo-Calc 2020 and JMatPro software.

\section{Experimental Work}

\subsection{Thermodynamics and Kinetics Calculations}

CSP plant involves continuous casting (thin slab caster TSC) to cast the refined and alloyed steel into slab. Depending upon the plant layout, this slab either is cooled to ambient temperature, then reheated in tunnel furnace or directly charged to reheating furnace to raise its temperature from the casting temperature in the range of $850^{\circ} \mathrm{C}-900^{\circ} \mathrm{C}$ to the rolling temperature $1100^{\circ} \mathrm{C}$ to $1250^{\circ} \mathrm{C}$. The low temperature of the slab permits undesired primary $\mathrm{Nb}(\mathrm{C}, \mathrm{N})$ precipitate to be created. Therefore, the reheating temperature should be controlled to allow $\mathrm{Nb}(\mathrm{C}, \mathrm{N})$ to dissolve inside the slab before the HSM rolling mill stands are prepared to get the slab for rolling operation.

Figure 1 and Figure 2 show the equilibrium thermodynamic conditions

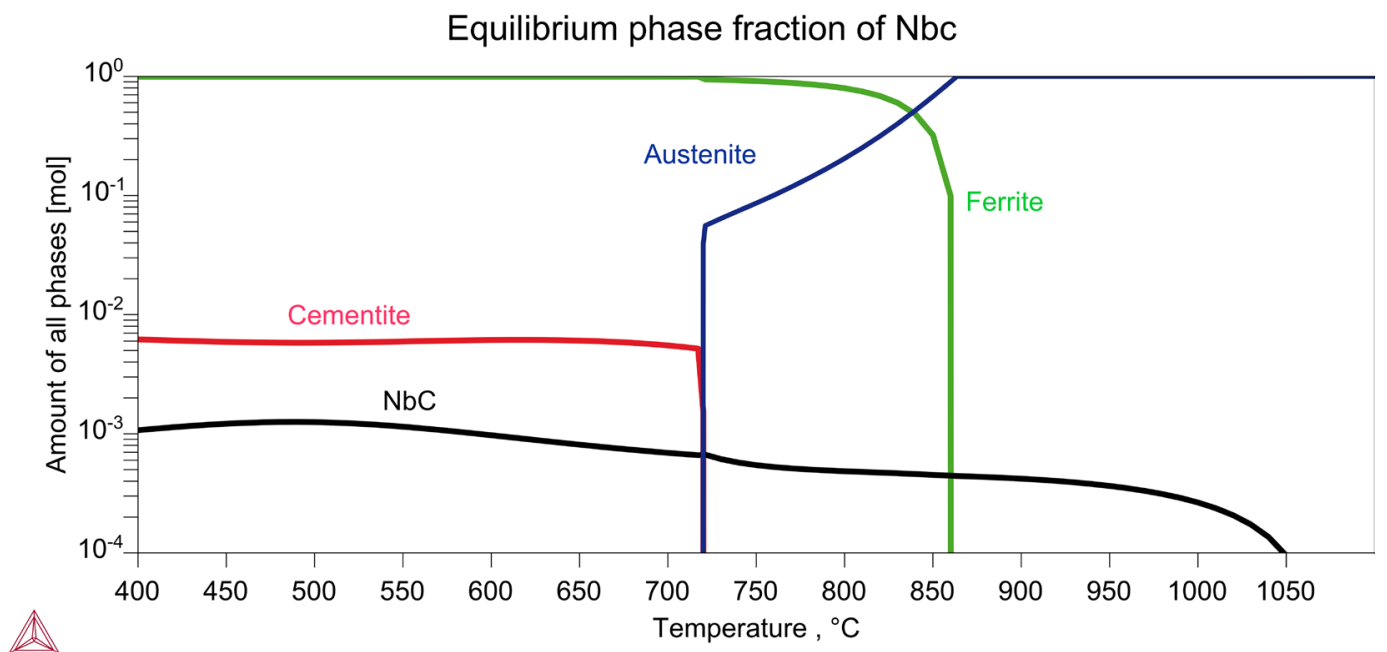

Figure 1. Equilibrium phase fraction of the decomposed phases. 


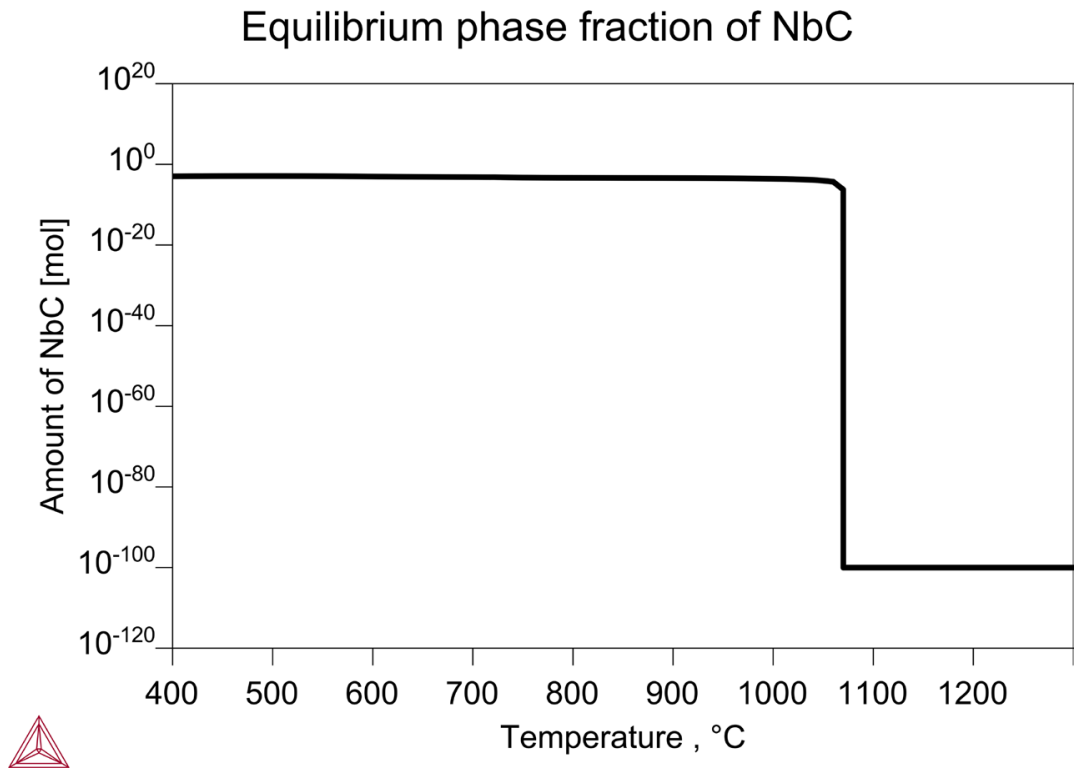

Figure 2. Dissolution temperatures of NbC precipitate.

are calculated by Thermo-Calc 2020. Figure 1 the type of phases and their volume fractions within the precipitation range, Figure 2 focuses on $\mathrm{Nb}(\mathrm{C}, \mathrm{N})$ phase precipitate. The calculations suggest that at equilibrium, $\mathrm{Nb}(\mathrm{C}, \mathrm{N})$ precipitates dissolve at a temperature close to $1050^{\circ} \mathrm{C}$. Thermodynamic calculations, at the equilibrium conditions, don't take into consideration the kinetics of carbide dissolution. Previous experimental studies proved that such alloy containing niobium needs enough time to allow the kinetics of $\mathrm{Nb}(\mathrm{C}, \mathrm{N})$ to dissolve, even the temperatures of $1100^{\circ} \mathrm{C}$ still not enough to accelerate the kinetics of entire dissolution of $\mathrm{Nb}(\mathrm{C}, \mathrm{N})$ [22] [23] [24]. Due to the nature of continuous production process of CSP plant, the normal buffer time allowed for slab reheating inside the tunnel furnace is 30 minutes, therefore a higher reheating temperature is selected as $1200^{\circ} \mathrm{C}-1250^{\circ} \mathrm{C}$ to increase the activation energy of dissolution kinetics of $\mathrm{Nb}(\mathrm{C}, \mathrm{N})$ and accelerate the dissolution process.

An important factor in the design of low carbon alloy for production in CSP plant is to keep away from the critical peritectic range, in order to avoid casting within the two phases " $\delta$ Ferrite $+\gamma$ austenite" region. To avoid this region (and to achieve considerable hardenability of the developed steel), several phase diagrams were plotted by Thermo-Calc 2020 for steel with low carbon composition and different alloying elements, then the material presented in Table 1 is selected.

Figure 3 shows the equilibrium phase diagram of the peritectic region for this alloy. The calculations demonstrate that this undesired region lies in the carbon content range from $0.0813 \mathrm{Wt} \%$ to $0.154 \mathrm{Wt} \%$ For the $\mathrm{CP}$-grade it should be far, with safe margin, from the lower border of the critical peritectic range. In this case, the extremely lower carbon content of 0.045 , would be favorable.

Figure 4 shows CCT diagram of the developed steel was plotted by JMat pro software. The prediction suggests that, due to its extremely low carbon content, high temperature ferrite phase transformation starts at a temperature between 
Peritectic reaction region of the phase diagram of DP alloy

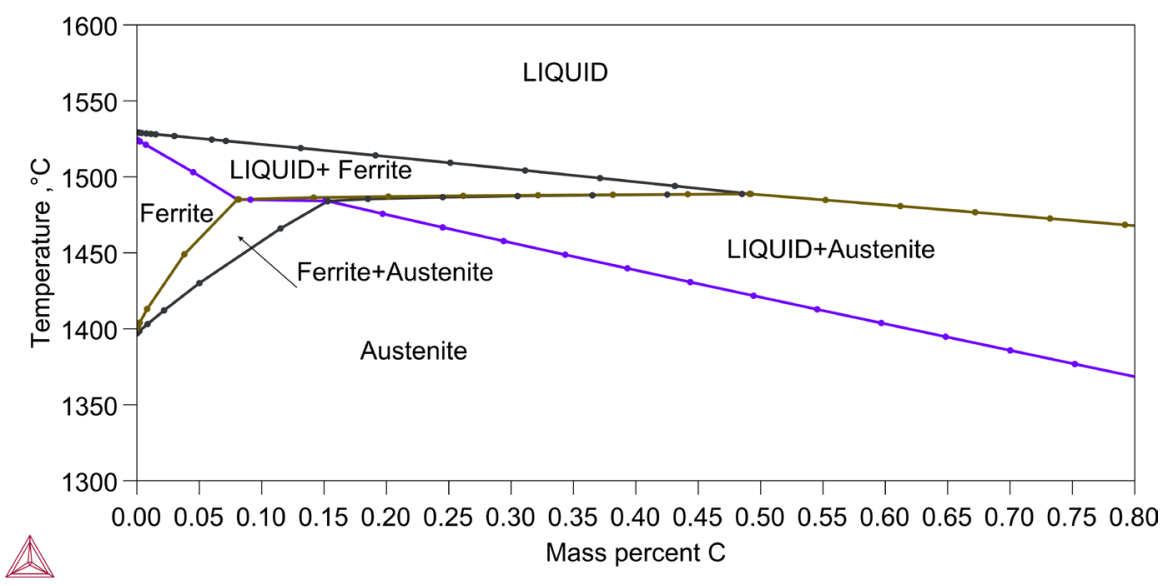

Figure 3. Peritectic reaction region of the developed DP alloy.

\section{CCT}

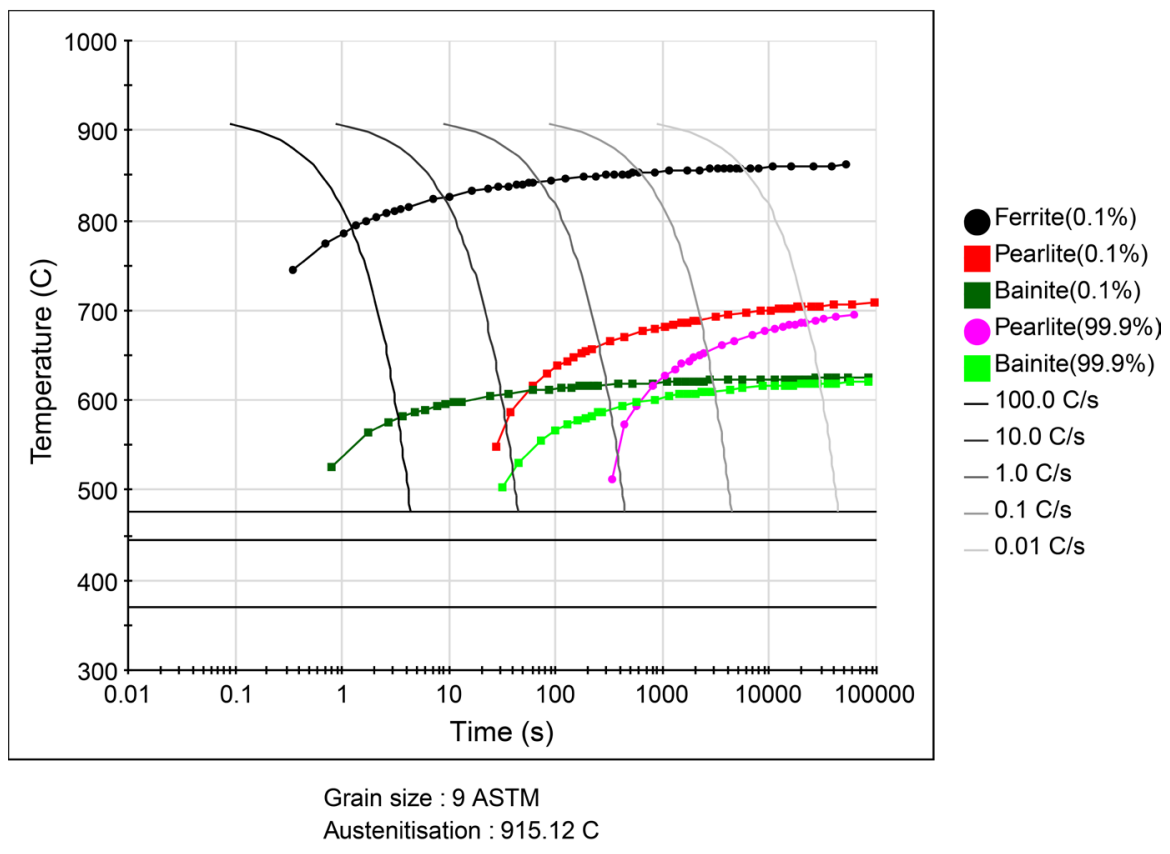

Figure 4. CCT curve of the tested DP alloy.

$850^{\circ} \mathrm{C}$ to $750^{\circ} \mathrm{C}$, while its nose is shifted towards a short time.

Figure 5 shows the carbon enrichment with reducing the austenite volume fraction calculated by Thermo-Calc 2020. This facilitates the formations of polygonal ferrite enough to create the soft matrix of $70 \%-80 \%$ volume fractions of polygonal ferrite. This major amount of transformed ferrite allows carbon enrichment of the non-transformed austenite and thus attaining a hardenability comparable with medium carbon steel with low carbon content of the base alloy.

\subsection{Materials}

Table 1 shows the chemical compositions of the developed DP alloy, this alloy 


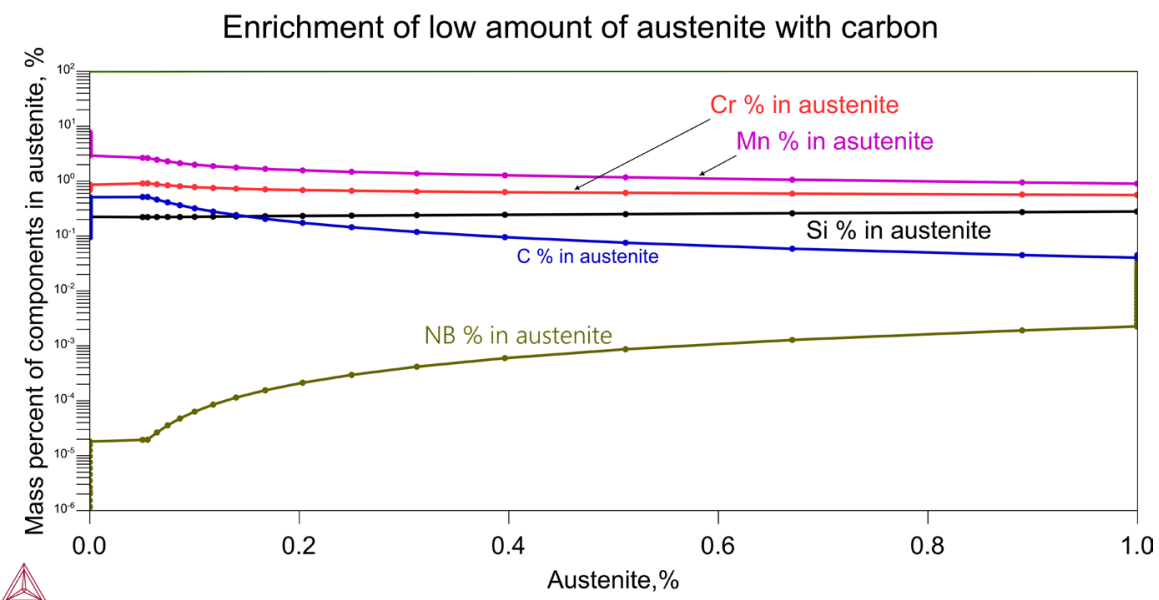

Figure 5. Carbon enrichment of the untransformed austenite.

Table 1. Chemical composition of the tested DP steel.

\begin{tabular}{cccccccccc}
\hline $\mathbf{C}$ & $\mathrm{Si}$ & $\mathrm{Mn}$ & $\mathrm{P}$ & $\mathrm{S}$ & $\mathrm{Cr}$ & $\mathrm{Ni}$ & $\mathrm{Nb}$ & $\mathrm{Ti}$ & $\mathrm{Al}$ \\
\hline 0.045 & 0.28 & 0.9 & 0.036 & 0.002 & 0.59 & 0.02 & 0.04 & 0.01 & 0.05 \\
\hline
\end{tabular}

was designed based on thermodynamic, kinetics calculation, the role of niobium as a micro alloying element in grain refining and the automotive requirement of low carbon content. This chemical composition matches with the standard composition of the most common DP steel grades 420,590, and 780, MPa. Which specify maximum alloying limits as $(0.14 \mathrm{Wt} \% \mathrm{C}, 2.5 \mathrm{Wt} \% \mathrm{Mn}$, $0.5 \mathrm{Wt} \% \mathrm{Si}, 1.4 \mathrm{Wt} \% \mathrm{Cr})$.

The aimed chemical composition was adjusted in an electrical arc furnace EAF and refined in ladle furnace LF in a compact slab production integrated plant. The charge mix feed to EAF composed of $80 \%$ direct reduced iron DRI and $20 \%$ steel scrap. As a result of the use of high pure steel (DRI), the tramp element content is extremely low, this is advantageous for strip quality. The chemical composition was determined to develop low carbon alloy which is considered main automotive requirement to achieve good weldability. As explained in thermodynamic calculation section, the carbon content of 0.045 was selected to avoid the peritectic region, at the same time it meets the weldability requirements. Niobium was used to obtain the micro-alloyed DP steel grades which are typically characterized by a very fine grained microstructure that allows to increase the strength and ductility at the same time. Si and $\mathrm{Cr}$ were added as a ferrite stabilizer and strengthening elements. $\mathrm{Mn}$ is added to retard the undesired pearlite formation and increase the strength of the ferrite matrix.

\subsection{Simulation of Thermomechanical Processing of HSM}

Different schedules were applied as presented in Table 2. To achieve the purpose of thermomechanical processing, recrystallization is to be delayed so that transformation starts from a strongly deformed austenite. This results in increasing the number of nucleation sites and hence the number of grains per unit volume. 
This is achieved by adding $\mathrm{Nb}$ of $0.04 \mathrm{Wt} \%$ as given in Table 1 . As calculated by Equation (1), the temperature of non-recrystallization Tnr, is found to be $986^{\circ} \mathrm{C}$. (Where $\mathrm{Nb}$ is the niobium percent and $\mathrm{V}$ is vanadium).

$$
\operatorname{Tnr}=849-349 \mathrm{C}+676 \sqrt{\mathrm{Nb}}+337 \mathrm{~V}
$$

The reheating temperature was determined by Thermo-Calc 2020. This temperature allows the dissolution of carbonitrides of micro alloying elements $(\mathrm{Nb})$ in austenite during reheating in tunnel furnace. The compression specimens of the physical simulator were machined to a flat shape. Each schedule was repeated twice to generate two identical specimens one for microstructure examinations and the second for tensile test. In order to completely dissolve the $\mathrm{Nb}$ carbonitrides, the specimens were then heated to a temperature of $1200^{\circ} \mathrm{C}$ for 30 minutes. The heated specimens were subjected to subsequent deformation consisting of 6 passes to simulate the reduction takes place in HSM of reducing the initial slab thickness to a final sheet thickness. Table 3 shows the applied deformation temperatures and strain rates (the given temperatures of FRT of $840^{\circ} \mathrm{C}$, when other FRT were applied, cascade change in the previous deformation temperatures were considered with respect to the temperature drop percentage per each stand).

Figure 6 shows the cooling schedule of the tested steel. The tested temperatures are finishing rolling temperature FRT and coiling temperature C.T. This consists of 1) accelerated cooling at a rate of $80^{\circ} \mathrm{C} \cdot \mathrm{S}^{-1}$ till reaching isothermal ferrite holding IFH temperature of $650^{\circ} \mathrm{C}, 2$ ) holding for different times of 7,6 , $4 \mathrm{~S}$. to allow enough ferrite formation, 3) accelerated cooling at a rate of $\left.80^{\circ} \mathrm{C} \cdot \mathrm{S}^{-1}, 4\right)$ very slow cooling rate of 30 degrees per hour at the temperatures of

Table 2. Steel designations based up on the metallurgical temperatures.

\begin{tabular}{cccc}
\hline Steel designations & FRT & IFH time, Sec & C.T \\
\hline DP1 & 780 & 6 & 330 \\
DP2 & 780 & 6 & 250 \\
DP3 & 780 & 6 & 180 \\
DP4 & 780 & 7 & 200 \\
DP5 & 780 & 4 & 200 \\
DP6 & 830 & 6 & 200 \\
DP7 & 820 & 6 & 200 \\
DP8 & 780 & 6 & 200 \\
\hline
\end{tabular}

Table 3. Deformation parameters.

\begin{tabular}{ccccccc}
\hline & Stand 1 & Stand 2 & Stand 3 & Stand 4 & Stand 5 & Stand 6 \\
\hline Temperatures & 1030 & 962 & 935 & 905 & 856 & 830 \\
Strain rate, $\mathrm{s}^{-1}$ & 5.15 & 15.52 & 37.54 & 67.17 & 82 & 90 \\
Inter pass time, S & 2.5 & 1.5 & 1 & 0.7 & 0.5 & 0.4 \\
\hline
\end{tabular}


$330^{\circ} \mathrm{C}, 250^{\circ} \mathrm{C}, 200^{\circ} \mathrm{C}$ and $180^{\circ} \mathrm{C}$, thus to simulate coiling process, 5) finally free cooling in ambient temperature.

Figure 7 shows the photos captured by thermo-graphic camera presents the thermal profile of the coil at different times during coil formation inside down coiler and after coil formation. These photos lead to exact simulation of the real industrial coiling process by measuring the coil temperature of $2 \mathrm{~mm}$ thickness by thermo-graphic camera at different times and record the obtained values and the average temperature drop was found $30^{\circ} \mathrm{C}$ per hour.

\subsection{Microstructure Examination}

The specimens were prepared using standard abrasive grinding papers started with coarse ones of 180 grit followed by gradually fine grinding papers reached to 1200 grit at the last grinding stage, then cold mounted in epoxy. The samples were examined by light optical microscope after etching with $4 \%$ nital etchant. Martensite volume fraction was determined by point count method according to ASTM E562 [25]. Ferrite grain size was measured according to ASTM E112 by linear intercept method [26]. Higher magnifications scanning with SEM and

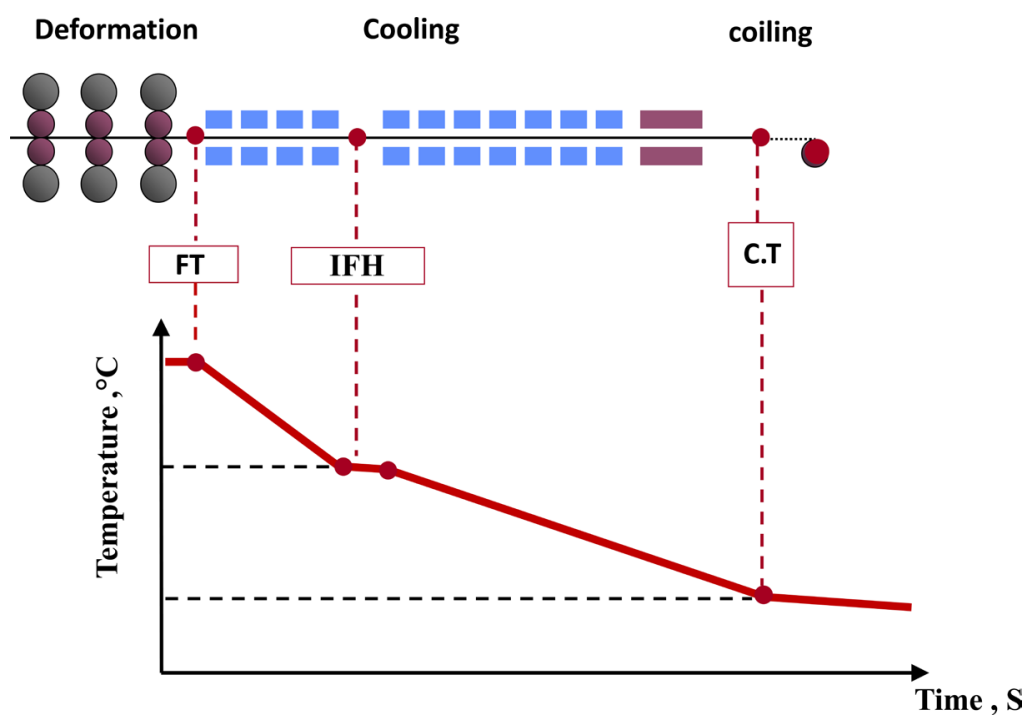

Figure 6. Cooling schedule of the tested steel.
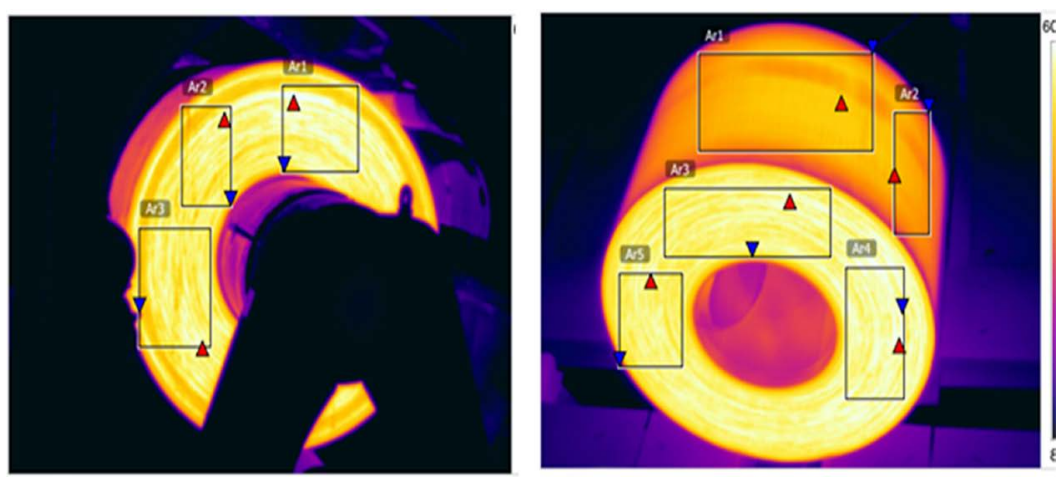

Figure 7. Thermal image of the coil during and after coiling process. 
TEM were performed for samples of different coiling temperatures.

\subsection{Tensile Examination}

The tensile test specimens were machined in accordance to ASTM standard E8-13. The tensile test was carried out using universal testing machine, at room temperature, with strain rate of $5 \times 10^{-4} \mathrm{~S}^{-1}$ and yield strength was calculated as the $0.2 \%$ offset [27].

\section{Results and Discussions}

\subsection{Microstructure Features}

\subsubsection{Effect of C.T}

Figure 8 shows the microstructure of the processed steel at similar rolling parameters and post rolling cooling schedule; namely FRT of $780^{\circ} \mathrm{C}$, cooling rate of $80^{\circ} \mathrm{C} \cdot \mathrm{S}^{-1}$, IFH temperature of $650^{\circ} \mathrm{C}$ for 6 seconds, and varying C.T of $330^{\circ} \mathrm{C}$, $250^{\circ} \mathrm{C}$ and $180^{\circ} \mathrm{C}$. Microstructure investigation indicates the presence of a homogeneously distributed mostly equiaxed ferrite grain with an average size of $(4 \mu \mathrm{m})$. as shown in Figure 8. Some of the grains appear elongated in shape which can be related to a subsequent deformation following the refinement transformation. The graphs do not reveal any micro-cracks or voids linked to martensite islands or elongated Mn-sulfides. The volume fraction of martensite increases from $29 \%$ to $32 \%$ with decreasing the C.T from $330^{\circ} \mathrm{C}$ to $180^{\circ} \mathrm{C}$. Although this can't be considered as a significant trend, however the tensile properties which will be presented in the next parts demonstrated a significant increase of Y.S and T.S. To investigate the effect of C.T on the tensile properties, regardless its negligible effect on the decomposed martensite volume fraction (TEM examination was performed).

Figure 9 shows high magnification TEM tests on specimen's presents coiling at C.T of $330^{\circ} \mathrm{C}, 250^{\circ} \mathrm{C}$ and $180^{\circ} \mathrm{C}$. The figure demonstrated that no significant differences of the DP microstructure were observed for specimens coiled at lower temperatures of $250^{\circ} \mathrm{C}$ and $180^{\circ} \mathrm{C}$. Both consists of martensite with heterogeneous orientations and very small carbides particles inside the single lath. This is in contrast to the demonstrated martensite morphology at higher C.T, where a remarkable change in martensite morphology was detected in the specimen presents the higher C.T of $330^{\circ} \mathrm{C}$ as indicated at Figure $9(\mathrm{c})$. When the C.T was increased to $330^{\circ} \mathrm{C}$, carbides precipitates are observed, these carbides
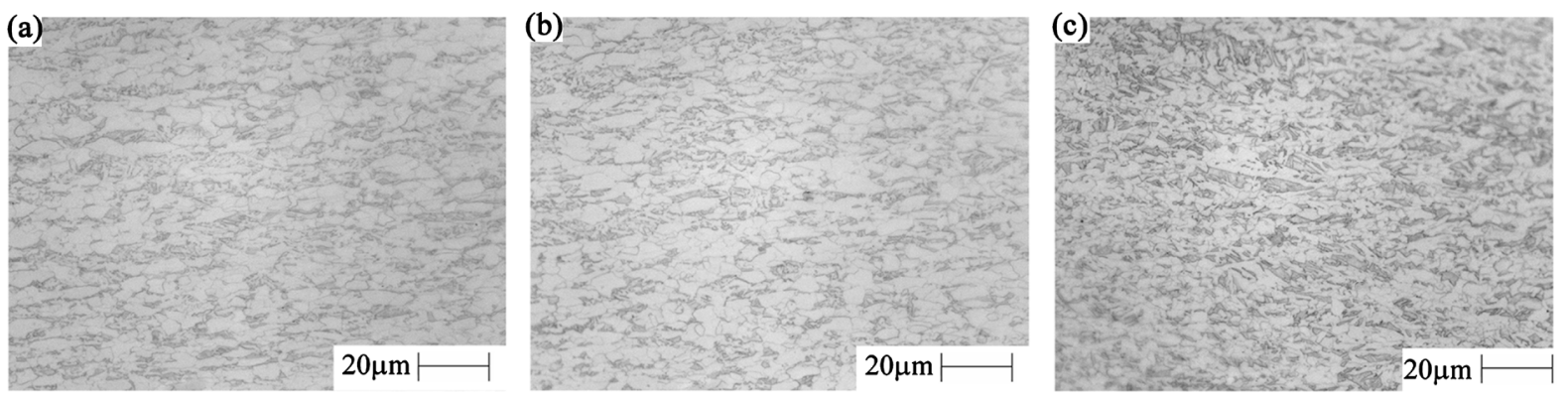

Figure 8. LOM microstructures at: (a) C.T $330^{\circ} \mathrm{C}$, (b) C.T $250^{\circ} \mathrm{C}$ and (c) C.T $180^{\circ} \mathrm{C}$. 
indicates that self-tempering phenomena of the quenched martensite takes place, then tempered martensite was obtained, due to long holding at $330^{\circ} \mathrm{C}$ under the effect of trapping the heat inside the coil during and after coil formation. Although that led to softening of martensite and decreased in tensile strength and strain hardening ability, however higher post-necking elongation is observed.

Figure 10 shows ferrite dislocations densities of C.T $330^{\circ} \mathrm{C}$ and C.T $180^{\circ} \mathrm{C}$. The figures demonstrate that higher ferrite dislocation density of the DP steel coiled at temperature of $180^{\circ} \mathrm{C}$ compared with the lower dislocation density of the DP steel coiled at high C.T of $330^{\circ} \mathrm{C}$. This result matches with a study by Shao-Pu Tsai et al. [28], where increasing dislocation density in ferrite matrix of DP steel, results in increasing the yield strength but differs in mechanism of increasing the dislocation density. In the present work, the dislocation density
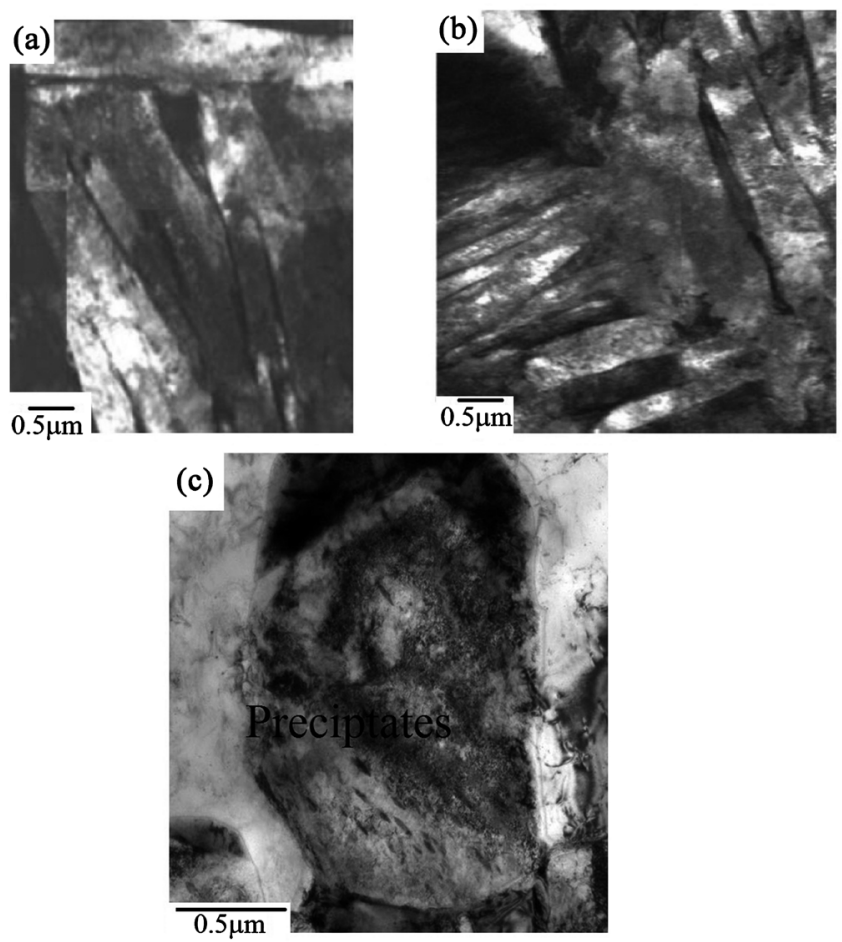

Figure 9. TEM micrograph at different C.T: (a) $180^{\circ} \mathrm{C}$ (b) $250^{\circ} \mathrm{C}$, (c) $330^{\circ} \mathrm{C}$.
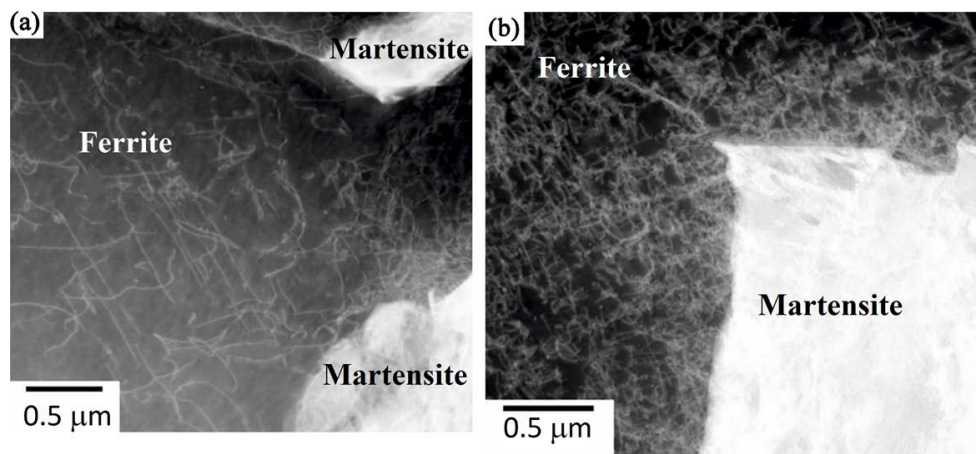

Figure 10. Ferrite dislocations density of DP steel coiled at different C.T temperatures: (a) $330^{\circ} \mathrm{C}$, (b) $180^{\circ} \mathrm{C}$. 
increased due to the effect of C.T while in the study conducted by Shao-Pu Tsai et al. dislocations density increased as a result of titanium precipitates [28]. Therefore coiling temperature could be considered a control function to tailor the strength and ductility balance required by the end service application.

\subsubsection{Effect of Isothermal Ferrite Holding IFH Time}

Figure 11 shows the LOM of the tested steel under IFH time of 7 and 4 seconds respectively. IFH time is designed to allow the formation of polygonal ferrite, which should have formed with enough quantities (70 - $80 \mathrm{wt} \%)$ to form the soft ferrite matrix, then the untransformed austenite quenched to form the hard phase (martensite). The effect of adjustment this time as 7 and 4 seconds was studied. When the IFH time was decreased from 7 to 4 seconds, while coiling temperature was constant at $200^{\circ} \mathrm{C}$, the martensite volume fraction of the tested steel is found to increase from $30 \%$ to $40 \%$. This can be attributed to a drop in the decomposition of the polygonal ferrite from $70 \%$ to $60 \%$, since the short isothermal ferrite holding time doesn't allow the kinetics of diffusion transformation of ferrite to nucleate and grow.

\subsection{Effect of Finishing Rolling Temperature FRT}

Figure 12. Shows the microstructure with LOM of the tested DP steel at different FRT: $830^{\circ} \mathrm{C}, 820^{\circ} \mathrm{C}$ and $790^{\circ} \mathrm{C}$. FRT was varied as $830^{\circ} \mathrm{C}, 820^{\circ} \mathrm{C}$, and $790^{\circ} \mathrm{C}$, while other parameters were kept constant and C.T was kept constant as $200^{\circ} \mathrm{C}$. The results show that decreases the FRT leads to increases of the ferrite volume fraction, this could be attributed to the formation of deformation induced ferrite while rolling takes place at the intercritical region. This argument is being supported by the elongated grains, as shown in Figure 12. This indicates that austenite to ferrite phase transformation had already started in the last stands of the finishing line. In the same figure, there is equiaxed polygonal ferrite, which was later formed during the post rolling cooling phase and during IFH at temperature of $650^{\circ} \mathrm{C}$.

\subsection{Tensile Properties}

Figure 13 shows the tensile properties of the developed DP steel which match with the typical DP steel tensile behavior found in the literatures [1] [9] [13] [16]
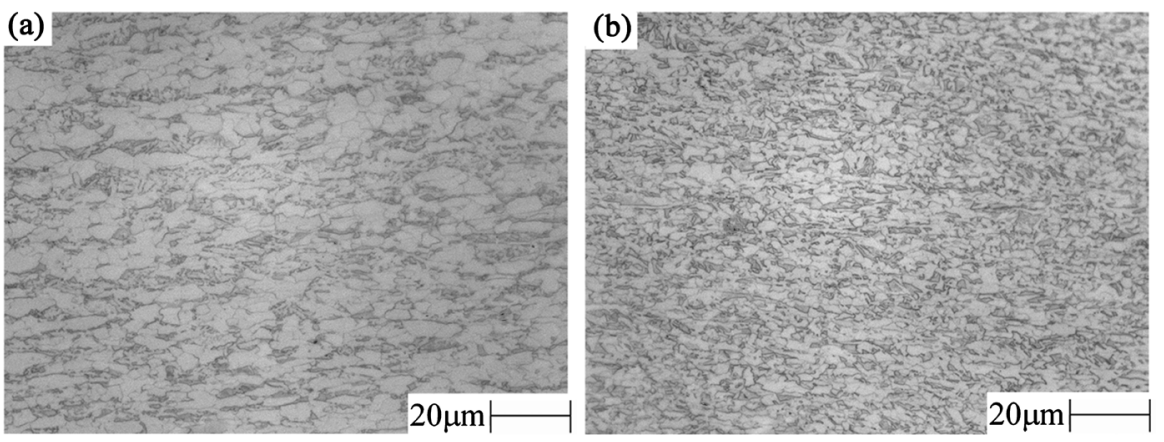

Figure 11. Microstructure with LOM of the testes DP steel at different IFH: (a) 7 S, (b) 4 S. 

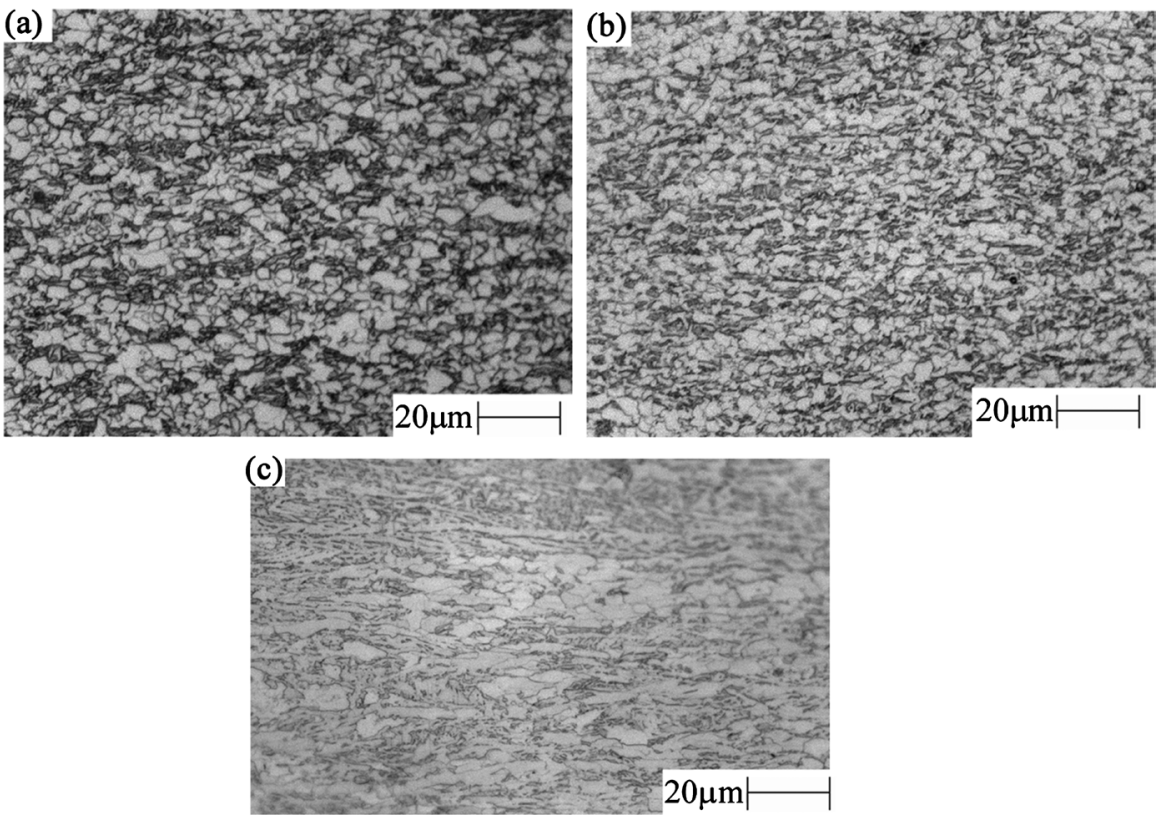

Figure 12. Microstructure with LOM of the testes DP steel at different FRT: (a) $830^{\circ} \mathrm{C}$, (b) $820^{\circ} \mathrm{C}$, (c) $790^{\circ} \mathrm{C}$.

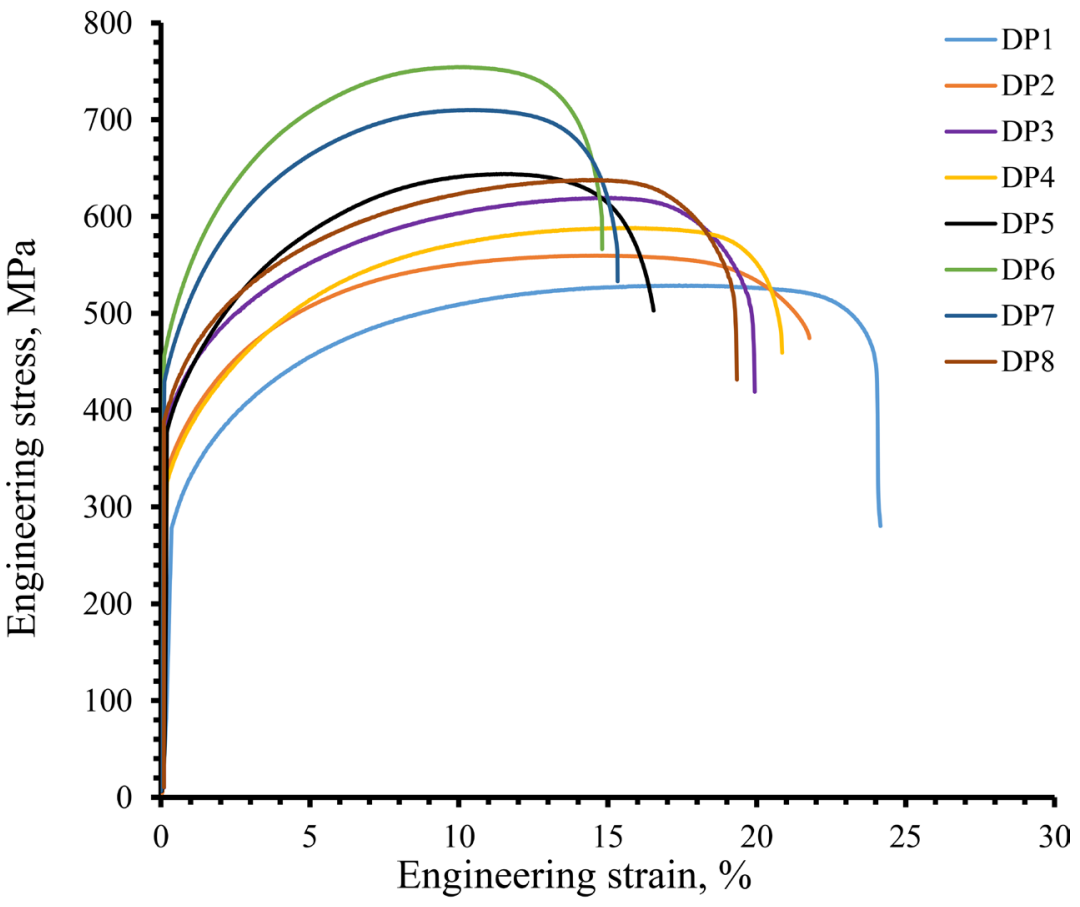

Figure 13. Tensile test of the investigated DP steels.

and [20], which characterized of high strain hardening and absence of yield point. Its remarkably varies with changing IFH time, FRT and C.T. temperatures. As demonstrated by the tensile curves of DP1, DP2, DP3, higher coiling temperature of $330^{\circ} \mathrm{C}$ achieves the lowest Y.S and T.S, while it achieves the higher post necking elongation. This is evidenced by microstructure shown in Figures 9(a)-(c) which shows carbides precipitates at the DP steel coiled at 
$330^{\circ} \mathrm{C}(\mathrm{c})$, while these carbides precipitates are absent in the DP steel coiled at lower temperatures of $250^{\circ} \mathrm{C}$ and $180^{\circ} \mathrm{C}$. These precipitates indicate the self-tempering process accrued during coiling process and the slow cooling of the coil. This besides of the increase in the ferrite dislocations density of the DP steel coiled at 180 compared with the DP steel coiled at higher temperature $330^{\circ} \mathrm{C}$ as demonstrated in Figure 10(a) \& Figure 10(b). The Curves of DP4 and DP5 reveal that decreasing IFH time from 7 to 4 second, leads to increase in strength. This is due to the decrease of allowed time for ferrite formation and therefore higher martensite formation takes place of the untransformed austenite during quenching. Increasing FRT of the specimens DP6, DP7, and DP8 resulted in higher strength values due to the decrease of the ferrite formation compared with the lower FRT. This could be explained by the formation of deformation induced ferrite at lower temperature and therefore the amount of untransformed austenite available to decompose to martensite decreases. On contrast, at higher FRT the amount of ferrite formations decreases compared with lower temperature, this allows the increase of the amount of untransformed austenite ready to transform to martensite during the subsequent accelerated cooling process.

\section{Conclusions}

1) Due to the sophisticated nature of CSP plant, limited cooling time which is available at run out table after the rolling process, thermodynamics and kinetics prediction were executed prior to the simulation of the HSM production process to design proper material and thermomechanical schedule, this allows reducing the costly trails in the industrial CSP plant, attains the desired DP microstructure and the tensile properties. Based upon automotive requirements of low carbon DP steels, thermodynamics calculations were used to design ultra-low carbon with free-cracks slab in the safe pre-peritectic region.

2) Dual phase microstructure could be produced and tailored in compact slab production plant by adjusting coiling temperature, finishing rolling temperature and isothermal holding time at a higher transformation temperature of ferrite.

3) Higher coiling temperature of $330^{\circ} \mathrm{C}$ leads to the formation of tempered martensite, thus this softening the DP steel. However, low coiling temperature of $250^{\circ} \mathrm{C}$ and $180^{\circ} \mathrm{C}$ lead to formation of higher strength quenched martensite with higher ferrite dislocation density.

4) Decreases of IFH time from 7 to 4 seconds result in decreasing the ferrite formation, thus increasing martensite volume fractions and the tensile properties. Decrease of the FRT in the two-phase (ferrite austenite) region, causes increase in ferrite formations. Therefore, the amount of non-transformed austenite is ready to decompose to martensite during quenching decreases, and consequently the tensile strength decreases.

\section{Conflicts of Interest}

The authors declare no conflicts of interest regarding the publication of this 
paper.

\section{References}

[1] Kumar, N., Gulab, M.J. and Kumar, B.R. (2019) Importance of Martensite Spatial Distribution at Large Volume Fractions in Imparting Ductility in High-Strength Dual-Phase Steel. Journal of Materials Engineering and Performance, 28, 1391-1401. https://doi.org/10.1007/s11665-019-03890-X

[2] Peng, F., Xu, Y., Li, J., Gu, X. and Wang, X. (2019) Interaction of Martensite and Bainite Transformations and Its Dependence on Quenching Temperature in Intercritical Quenching and Partitioning Steels. Materials and Design, 181, Article ID: 107921. https://doi.org/10.1016/j.matdes.2019.107921

[3] Dai, J., Meng, Q. and Zheng, H. (2020) High-Strength Dual-Phase Steel Produced through Fast Heating Annealing Method. Results in Materials, 5, Article ID: 100069. https://doi.org/10.1016/j.rinma.2020.100069

[4] Shukla, N., Das, S., Maji, S., Chowdhury, S.R. and Show, B.K. (2015) Effect of Pre-Intercritical Annealing Treatments on the Microstructure and Mechanical Properties of 0.33\% Carbon Dual-Phase Steel. Journal of Materials Engineering and Performance, 24, 4958-4965. https://doi.org/10.1007/s11665-015-1750-4

[5] Zhao, X., Huang, B., Chen, H., Ma, J., Wang, C. and Yang, Y. (2020) Influence of Intercritical Quenching Temperature on Microstructure, Mechanical Properties and Corrosion Resistance of Dual-Phase Steel. Journal of Materials Engineering and Performance, 29, 4446-4456. https://doi.org/10.1007/s11665-020-04928-1

[6] Deng, Y.G., Li, Y., Di, H. and Misra, R.D.K. (2019) Effect of Heating Rate during Continuous Annealing on Microstructure and Mechanical Properties of High-Strength Dual-Phase Steel. Journal of Materials Engineering and Performance, 28, 4556-4564. https://doi.org/10.1007/s11665-019-04253-2

[7] Srivastava, A.K., Patel, N.K., Kumar, B.R., Sharma, A. and Ahn, B. (2020) Strength-Ductility Trade-Off in Dual-Phase Steel Tailored via Controlled Phase Transformation. Journal of Materials Engineering and Performance, 29, 2783-2791. https://doi.org/10.1007/s11665-020-04799-6

[8] Furukawa, T., Tanion, M., Morikawa, H. and Endo, M. (1984) Effects of Composition and Processing Factors on the Mechanical Properties of As-Hot-Rolled Dual-Phase Steels. Transactions of the Iron and Steel Institute of Japan, 4, 113-121. https://doi.org/10.2355/isijinternational1966.24.113

[9] Ji, L.K., Xu, T., Zhang, J.M., Wang, H.T., Tong, M.X., Zhu, R.H. and Zhou, G.S. (2017) The Microstructure Evolution of Dual-Phase Pipeline Steel with Plastic Deformation at Different Strain Rates. Journal of Materials Engineering and Performance, 26, 3104-3111. https://doi.org/10.1007/s11665-017-2694-7

[10] Kumar, S. and Desai, R. (2019) Effect of Boron Micro-Alloying on Microstructure and Corrosion Behavior of Dual-Phase Steel. Journal of Materials Engineering and Performance, 28, 6228-6236. https://doi.org/10.1007/s11665-019-04364-w

[11] Saastamoinen, A., Kaijalainen, A., Porter, D. and Suikkanen, P. (2017) The Effect of Thermomechanical Treatment and Tempering on the Subsurface Microstructure and Bendability of Direct-Quenched Low-Carbon Strip Steel. Materials Characterization, 134, 172-181. https://doi.org/10.1016/j.matchar.2017.10.020

[12] Xu, S.S., Li, J.P., Cui, Y., Zhang, Y., Sun, L.X., Li, J., Luan, J.H., Jiao, Z.B., Wang, L., Liu, C.T. and Zhang, Z.W. (2020) Mechanical Properties and Deformation Mechanisms of a Novel Austenite-Martensite Dual Phase Steel. International Journal of 
Plasticity, 128, Article ID: 102677. https://doi.org/10.1016/j.ijplas.2020.102677

[13] Chen, C.Y., Lib, C.H., et al. (2020) A Novel Technique for Developing a Dual-Phase Steel with a Lower Strength Difference between Ferrite and Martensite. Materials Today Communications, 23, Article ID: 100895. https://doi.org/10.1016/j.mtcomm.2020.100895

[14] Calcagnotto, M., Ponge, D. and Raabe, D. (2010) Effect of Grain Refinement to 1 $\mu \mathrm{m}$ Strength and Toughness of Dual-Phase Steels. Materials Science and Engineering $A$, 527, 7832-7840. https://doi.org/10.1016/j.msea.2010.08.062

[15] Calcagnotto, M., Adachi, Y., Ponge, D. and Raabe, D. (2011) Deformation and Fracture Mechanisms in Fine- and Ultrafine-Grained Ferrite/Martensite Dual-Phase Steels and the Effect of Aging. Acta Materialia, 59, 658-670.

https://doi.org/10.1016/j.actamat.2010.10.002

[16] Zhao, Z., Wang, X., Qiao, G., Zhang, S., Liao, B. and Xiao, F. (2019) Effect of Bainite Morphology on Deformation Compatibility of Mesostructure in Ferrite/Bainite Dual-Phase Steel: Mesostructure-Based Finite Element Analysis. Materials and Design, 180, Article ID: 107870. https://doi.org/10.1016/j.matdes.2019.107870

[17] Soliman, M. and Palkowski, H. (2015) Influence of Hot Working Parameters on Microstructure Evolution, Tensile Behavior and Strain Aging Potential of Bainitic Pipeline Steel. Materials and Design, 88, 759-773.

https://doi.org/10.1016/j.matdes.2015.09.040

[18] Podder, A.S., Murugaiyan, A., Pandit, A., Chandra, S., Bhattacharjee, D. and Ray, R. (2006) Phase Transformations in Two C-Mn-Si-Cr Dual Phase Steels. ISIJ International, 46, 1489-1494. https://doi.org/10.2355/isijinternational.46.1489

[19] Gurumurthy, B., Sharma, S. and Kini, A. (2018) Ferrite-Bainite Dual Phase Structure and Mechanical Characterization of AISI 4340 Steel. Materials Today. Proceedings, 5, 24907-24914. https://doi.org/10.1016/j.matpr.2018.10.290

[20] Soliman, M. and Palkowski, H. (2020) Tensile Properties and Bake Hardening Response of Dual Phase Steels with Varied Martensite Volume Fraction. Materials Science \& Engineering A, 777, Article ID: 139044.

https://doi.org/10.1016/j.msea.2020.139044

[21] Bleck, W., Hömberg, D., Suwanpinij, U. and Togobytska, P. (2014) Optimal Control of a Cooling Line for Production of Hot Rolled Dual Phase Steel. Steel Research International, 85, 1328-1333. https://doi.org/10.1002/srin.201300253

[22] Olasolo, M., Uranga, P., Rodriguez, M. and Lopez, B. (2011) Effect of Austenite Microstructure and Cooling Rate on Transformation Characteristics in a Low Carbon Nb-V Microalloyed Steel. Materials Science and Engineering A, 528, 2559-2569. https://doi.org/10.1016/j.msea.2010.11.078

[23] Mecozzi, M.G., Sietsma, J. and Van der Zwaag, S. (2006) Analysis of $\gamma \rightarrow \alpha$ Transformation in a Nb Micro-Alloyed C-Mn Steel by Phase Field Modelling. Acta Materialia, 54, 1431-1440. https://doi.org/10.1016/j.actamat.2005.11.014

[24] Lee, H.-Y., Park, K.-S., Lee, J.-H., Heo, Y.-U., Suh, D.-W. and Bhadeshia, H.K.D.H. (2014) Dissolution Behavior of NbC during Slab Reheating. ISIJ International, 54, 1677-1681. https://doi.org/10.2355/isijinternational.54.1677

[25] ASTM Int. (2019) ASTM E562-19, Standard Test Method for Determining Volume Fraction by Systematic Manual Point Count.

[26] ASTM Int. (2013) ASTM E112-13, Standard Test Methods for Determining Average Grain Size.

[27] ASTM Int. (2013) ASTM E8-13a, Standard Test Methods for Tension Testing of 
Metallic Materials.

[28] Tsai, S.-P., Jen, C.-H., Yen, H.-W., Chen, C.-Y., et al. (2017) Effects of Interphase TiC Precipitates on Tensile Properties and Dislocation Structures in a Dual Phase Steel. Materials Characterization, 123, 153-158.

https://doi.org/10.1016/j.matchar.2016.11.023 